\title{
Do I win, does the company win, or do we both win? Moderate traits of the Dark Triad and profit maximization
}

\author{
Márcia Figueredo D'Souza ${ }^{1}$ \\ (D) https://orcid.org/0000-0002-3196-5396 \\ Email: marciafdsouza@yahoo.com.br \\ Gerlando Augusto Sampaio Franco de Lima ${ }^{2}$ \\ (D) https://orcid.org/0000-0002-2414-2543 \\ Email: gerlando@illinois.edu \\ Daniel N. Jones ${ }^{3}$ \\ Email: dnjones3@utep.edu \\ Jessica R. Carré ${ }^{3}$ \\ Email: jrcarre@miners.utep.edu \\ ${ }^{1}$ Universidade do Estado da Bahia, Departamento de Ciências Humanas e Tecnologia, Camaçari, BA, Brazil \\ ${ }^{2}$ University of Illinois at Urbana-Champaign, College of Business, Department of Accountancy, Champaign, IL, United States of America \\ ${ }^{3}$ University of Texas at El Paso, Psychology Institute, El Paso, TX, United States of America
}

Received on 06.09.2017 - Desk acceptance on 07.11.2017 - $2^{\text {nd }}$ version approved on 12.08.2017 - Ahead of print on 10.08.2018

Associate Editor: Fernanda Finotti Cordeiro Perobelli

\begin{abstract}
This article analyzes the relationship between the maximization of personal and company gains and the moderate traits of the Dark Triad. The relevance of choosing this topic lies in investigating the attitude of executives who exhibit characteristics of a moderate intensity between the strong and weak traits. It is proven that the vision and charisma of narcissistic individuals, the strategy and tactics of Machiavellian individuals, and the creativity and good strategic thinking of psychopathic individuals are differentiating characteristics that enhance successful and integrative leadership and that are far from the more accentuated and opportunistic attitudes related to the strong traits, whose practices involve dishonest actions for personal gain. This evidence creates the possibility for strengthening the research in the accounting area, especially on the behavioral approach, in order to promote its interface with psychology and clarify how personality, values, and experiences influence managers' choices when conducting business and how workers and companies are impacted by these decisions. The study is empirical-theoretical and involves 263 managers, adopting a survey as its data collection strategy and applying a selfreporting type questionnaire. The data analysis approaches included descriptive statistics, correlations, tests of means, and logistic regressions. In this study, managers with moderate psychopathic traits showed a lower tendency to maximize profit by manipulating results. An opposite tendency was revealed for those with moderate Machiavellian traits. The combined effect of the three Dark Triad traits was significant and positive, revealing opportunistic profit maximization. These findings contribute to future studies that aim to systematically analyze moderate levels of the triad and corroborate the findings that have revealed the common characteristics of manipulation, callousness, and dishonesty when investigating the interactive effect between the traits in question.
\end{abstract}

Keywords: Dark Triad, profit maximization, earnings management, accounting.

Correspondence address

Márcia Figueredo D'Souza

Universidade do Estado da Bahia, Departamento de Ciências Humanas e Tecnologia

Rodovia BA 512, Km 1,5 - CEP 42800-000

Santo Antônio - Camaçari - BA - Brazil 


\section{INTRODUCTION}

Profit maximization is a standard act in the area of business, but at times it reveals the opportunistic character of executives in their greed and desire to serve their own interests (Koch, 2010), especially when they are in possession of privileged information about the economic and financial position of a company or have knowledge of the weak points in a corporate governance structure and internal controls (Troy, Smith, \& Domino, 2011). As it is an important tool for determining management performance and a basis for calculating bonuses and compensation, accounting information becomes the target of manipulation for profit maximization purposes by those who seek personal and corporate success (Crocker \& Slemrod, 2007; Holthausen, Larker, \& Sloan, 1995; Healy, 1985).

Quirin, Beckenkamp, and Kuhl (2008) and Miller and Pazgal (2002) argue that profit maximization is intimately related with subjective factors, such as the personality of executives. The psychological theory of personality supports the studies from Babiak, Neumann and Hare (2010), Chatterjee and Hambrick (2007), Jain and Bearden (2011), Maccoby (2004), and Rosenthal and Pittinsky (2006) in their analysis of the relationship between the personality traits of narcissism, Machiavellianism, and psychopathy and the behavior of executives in the corporate environment, in light of the importance of analyzing the impact of these traits on financial reports (Majors, 2015; Amernic \& Craig, 2010; Johnson, Kuhn, Apostolou, \& Hassell, 2013; Olsen, Young, \& Dworkis, 2013), especially for detecting tendencies to commit fraud (Murphy, 2012; Cohen, Ding, Lesage, \& Stolowy, 2010), white collar crimes (Collins \& Schmidt, 1993; Blickle, Schlegel, Fassbender, \& Klein, 2006), and to engage in earnings management (Olsen \& Stekelberg, 2016; Ham, Lang, Seybert, \& Wang, 2017; Brown, 2014; Frino, Lim, Mollica, \& Palumbo, 2015; Buchholz, Lopatta, \& Maas, 2014; Jones, 2014; Rijsenbilt \& Commandeur, 2013; Shafer \& Wang, 2011; Boddy, 2006; Deutschman, 2005; McCormick \& Burch, 2005).

Studies of narcissistic, Machiavellian, and psychopathic traits have shown their importance in the accounting and organizational environment, using the personality psychology social approach, studied by Paulhus and Williams (2002) and revisited by Jones and Paulhus (2014). The authors called the triad the Dark Triad and verified that although there is a conceptual distinction there is convergence between the traits towards callousness and a disagreeableness. Individuals who are rich in these attributes also exhibit behavior with tendencies for self-promotion, emotional coldness, duplicity, and aggressiveness.

The tool for measuring the Dark Triad traits derived from the studies from Jones and Paulhus (2014) and Paulhus and Williams (2002), called the "Short Dark Triad" (SD3), has an attitudinal connotation that refers to the analysis of tendencies and predispositions towards characteristics spread throughout the population in general, and is based on a self-reporting questionnaire that enables the intensity with which an individual matches to be verified, without intending to make any clinical diagnosis (Almeida, Laranjeira, \& Dratcu, 1996).

Despite the negative connotation of these traits and the fact that many studies have addressed this particular issue, there is research that contradicts this line of thinking and shows their positive side. Studies on the narcissistic traits indicate that vision, charisma, innovation, the ability to attract followers, conducting business to gain power and glory, and an image that conveys the concept of a great leader are elements that can make those involved successful in the organizational environment (Campbell, Hoffman, Campbell, \& Marchisio, 2011; Chatterjee \& Hambrick, 2007; Maccoby, 2004; O’Reilly, Doerr, Caldwell, \& Chatman, 2013; Rosenthal \& Pittinsky, 2006), with a tendency for effective leadership (Rosenthal \& Pittinsky, 2006). Authority, self-sufficiency, and superiority are positive for organizational performance (Dworkis, 2013), as well as cognitive elements such as intelligence, creativity, competence, and leadership skills (Farwell \& WohlwendLloyd, 1998).

With regards to psychopathy, professionals from the area of business present a positive association between charisma, presentation style, creativity, good strategic thinking, and communication skills (Babiak et al., 2010). They can be charming (Boddy, 2006; Wexler, 2008). Bold dominance can positively influence general performance at work and communication (Smith \& Lilienfeld, 2013), enabling them to take difficult decisions using their courage, firmness, and vision (Wexler, 2008).

When analyzed, Machiavellians display strategy and management tactics (Jones \& Paulhus, 2011), are adaptable, able to contribute, cooperate, and use prosocial strategies, not only when this is advantageous for them (Belschak, Hartog, \& Kalshoven, 2015).

Thus, the objective of this study is to analyze the relationship between the maximization of personal and corporate gains and the moderate Dark Triad traits. This 
motivation finds support in Upper Echelons Theory (Hambrick \& Mason, 1984; Hambrick, 2007), which states that the characteristics of executives, such as personality, values, and experience, are reflected in organizational results and therefore in the choices and decision of managers. Studies that cover personality (Papadakis \& Barwise, 2002; Abatecola, Mandarelli, \& Poggesi, 2013) and the traits that compose the Dark Triad (Chatterjee \& Hambrick, 2007; Dworkis, 2013; Olsen \& Stekelberg, 2016), in the corporate and accounting environment, base their assumptions on Upper Echelons Theory, which is derived from Behavioral Theory of the Firm and Descriptive Theory.

We therefore seek to shed light of the following problem: what is the relationship between the maximization of personal and corporate gains and the moderate personality traits of the Dark Triad? Analyses of the attitude of executives that exhibit characteristics of a moderate intensity between the strong and weak traits contribute to the perception that the vision and charisma of narcissistic individuals, the strategy and tactics of Machiavellian individuals, and the creativity and good strategic thinking of psychopathic individuals can be differentiating characteristics that enhance successful and integrative leadership. They can also reveal that the efforts of these managers are geared towards achieving personal and corporate gains, without them engaging in accentuated negative attitudes and seeking only personal gains to the detriment of corporate gains and the combination of both, even if for this they harm their peers, subordinates, and the long-term interests of the company itself - as occurs when individuals exhibit strong Dark Triad traits.

In addition, as Brown (2014) states, most of the studies in the accounting area that analyze profit maximization via opportunistic actions examine how the gains are generated, how they can be detected, and what the consequences are. They have not considered that psychological factors can influence the attitudes of managers in the corporate context.

This investigation also provides a practical contribution for researchers, professionals, companies, and the population in general. The results may be shown to be useful for recruiting and selecting individuals to occupy leadership positions in which they are responsible for making financial decisions, whose choices are reflected in significant results for the organization. For example, hiring managers that display a moderate level of these traits may be beneficial for company performance.

Section 2 presents the theory and development of the research hypotheses in greater detail; section 3 describes the methodological approach adopted; section 4 discusses the results; and section 5 concludes this article.

\section{THEORY AND DEVELOPMENT OF THE HYPOTHESES}

\subsection{Profit Maximization}

Profit maximization, from a technical perspective, consists of a set of conditions in which a firm's marginal revenue is equal its marginal cost. This traditional notion lost expressiveness when the behavioral perspective of profit maximization emerged, which argues that the search for profit produces a type and quantity of products and services that are sufficient for consumption, at the lowest possible cost, thus contributing to business and common and personal wellbeing (Primeaux \& Stieber, 1994).

Quirin, Beckenkamp, and Kuhl (2008) stress the behavioral character of profit maximization and state that factors such as personality, propensities for power, and affective states influence decision-making behavior, although in an inconsistent way. Along this same line of thinking, Miller and Pazgal (2002) verified that a manager's personality, education, and leadership style can be used as strategic profit maximizing devices in certain environments, with the aim of influencing a competitive position in companies.

These findings corroborate with Upper Echelons Theory, proposed by Hambrick and Mason (1984) and revisited by Hambrick (2007), by showing that the characteristics of executives, such as personality, values, and experience, are reflected in organizational results and therefore in the choices and decisions of managers. This theory is derived from the studies that defend limited rationality in decision making in organizations and investigate the conflict of interests regarding the individual preferences of each participant (Cyert \& March, 1963; March \& Simon, 1958).

Considering the search for profit as a normal act, Koch (2010) argues that the overriding object of profit maximization is the continuity of operational activities and should not be restricted to fulfilling own interests or corporate greed. For the author, it is warranted for executives to see profit maximization as their main 
objective when conducting their business, providing they do break laws, norms, or social customs.

However, the search for profit does not always have a normal and positive character in the organizational environment. An opportunistic character is revealed when managers are unable to achieve company goals or meet the forecasts of analysts, investors, or other interested parties. This situation drives them to maximize profits by manipulating results in order to meet such expectations and those of themselves, especially when remuneration and bonuses are associated with the profits reported in financial statements (Healy, 1985).

In this context, it is worth being aware of subjective factors, such as personality traits, which are potential influencers of managers' attitudes in the corporate environment.

\subsection{Dark Triad: Narcissism, Machiavellianism, and Psychopathy}

Paulhus and Williams (2002) investigated the nonpathological personality traits of psychopathy, narcissism, and Machiavellianism - known as the Dark Triad - and found that they are moderately inter-correlated, have overlapping characteristics, which are cognitively related, but are presented as distinct constructs. These authors stated that the traits of the triad imply a "socially evil character with tendencies for self-promoting, emotionally cold, duplicitous, and aggressive behavior" (Paulhus \& Williams, 2002, p. 557).

For a better presentation of these personality types, based on the literature review, Figure 1 illustrates the respective individual, overlapping, and common attributes.

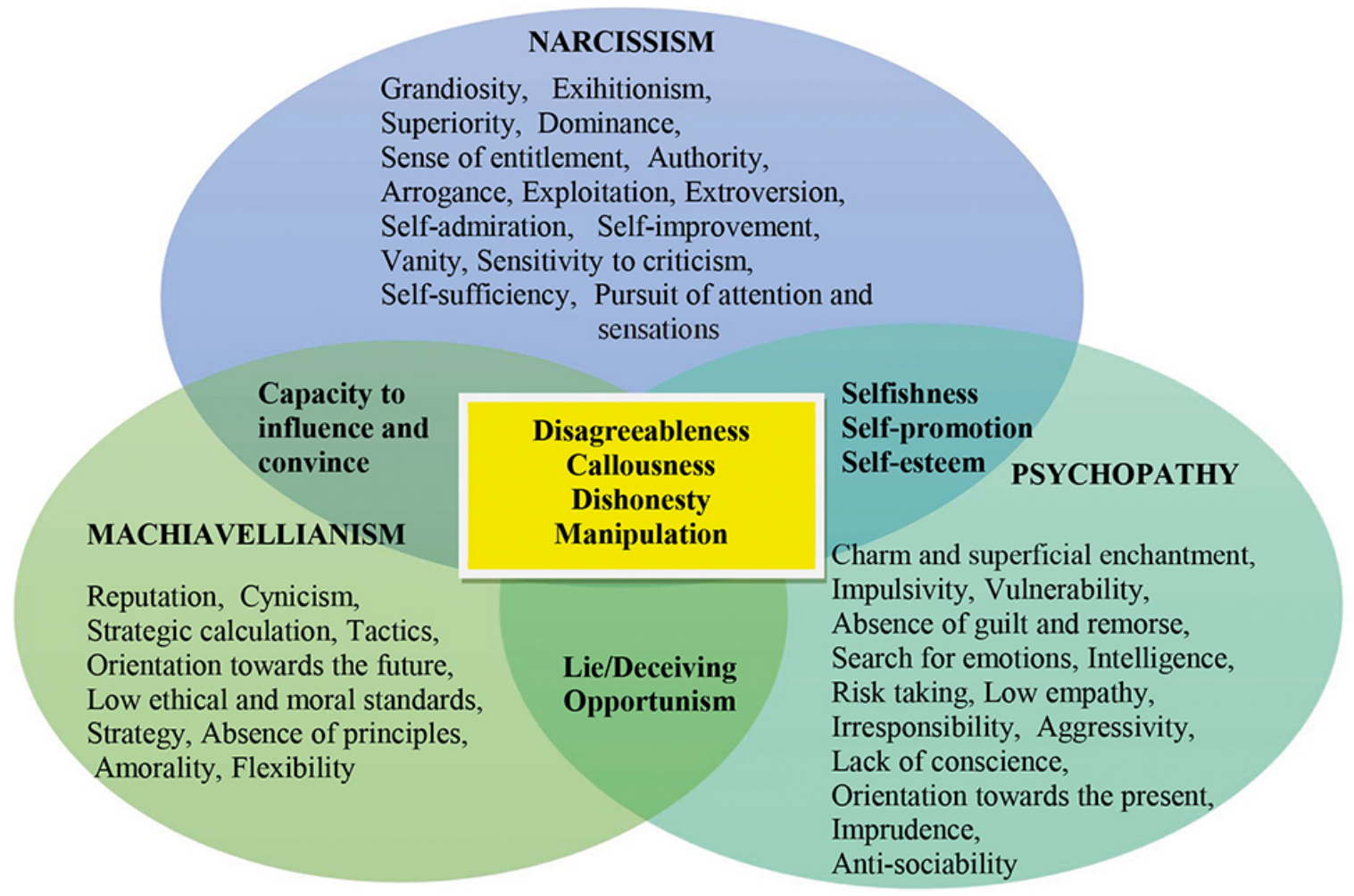

Figure 1 Main characteristics of the Dark Triad personality traits

Source: D'Souza (2016).

These attributes are not static since they constitute personality traits and can therefore alter depending on the circumstances being analyzed. It is also noted that to a greater or lesser degree some characteristics are more related to two personality traits, but can also be present to a lesser degree in relation to the other trait, such as egotism, which establishes a greater relationship with narcissism and psychopathy but is also discretely presented in the personal power behavior of Machiavellians.

In addition, as Jones and Figueredo (2013) state, the literature is full of debates about the antagonistic overlapping of the characteristics, observing that despite such characteristics being the same, the "objectives" or focuses proposed in them are different. For examples, 
Machiavellianism is a trait defined by manipulative, insensitive, and strategic tendencies. Psychopathy is also a trait that is defined by manipulation and insensitive tendencies, but the focus of the manipulation is short term and of a more antisocial nature. Narcissism, in turn, is also defined by manipulation and insensitivity, but the focus is geared towards self-promotion, in light of the self-inflated sense of ego.

It is also worth noting the non-clinical nature of the Dark Triad traits in this topic. On this point, Almeida et al. (1996) indicate that social psychology highlights characteristics normally spread throughout the population that are displayed via more flexible and adaptable attitudes - measured by statistical tests. As for the clinical focus, this conveys inflexible and maladaptive personality traits, causing significant functional impairment or subjective suffering to oneself or, more commonly, to individuals nearby (Mecler, 2015).

In this topic it is also worth discussing the difference between attitudes and behaviors. An attitude can be defined as a propensity to react to some stimulus in a positive or negative way (Fishbein \& Ajzen, 1975). Attitudes have three basic components: cognitive, affective, and behavioral. Cognitive covers beliefs and knowledge of stimuli and their assessment; affective refers to emotions; and behavioral is the tendency to behave in a certain way, reacting to one's own emotions and cognitions. Although attitudes can lead to an intention to behave in a certain way, the intention may not come about, depending on the situation or circumstances (Bowditch \& Buono, 1992).

An attitude can precede and influence behavior (Vaccari, 2014). As for behavior, this refers to the "specific actions directed towards an object-target, always occurring in a context or situational environment and at a particular time" (Peter \& Olson, 2009, p. 149). In organizational contexts, it involves a selection of particular actions, based on planning guided by objectives and goals (Simon, 1970). Therefore, attitudes are "the force of intention of an individual to carry out a specific behavior" (Fishbein \& Ajzen, 1975, p. 288).

In light of the concepts presented, it can be affirmed that personality traits are components that explain and influence attitudes and behaviors, but not in their entirety, given that other variables, such as abilities, motivations, emotions, values, habits, and sociocultural determinants also influence human conduct. A behavior is presented as a variable, momentary action that is not necessarily a long-lasting and particular characteristic of a person.
2.2.1. The Dark Triad traits in the organizational and accounting context: the good and the bad side.

\subsubsection{Narcissism.}

Campbell et al. (2011) state that characteristics of Narcissism are commonly identified in executives who hold senior management positions. These managers are praised for their passion, vision, and innovation; however, they are condemned for their lack of empathy and sensitivity to criticism. They have the ability to manipulate others, they are impulsive, and assume risks in their investment decisions, especially because of their excessive confidence. They have a talent for establishing quick and superficial relationships.

From this same descriptive viewpoint, Chatterjee and Hambrick (2007) argue that narcissistic chief executive officers (CEOs) take bold strategic decisions, which supposedly underline their talent as managers, consequently contributing to the success of their companies. However, Hobson and Resutek (2008) address the negative side of this attribute, pointing to evidence that in their aim to bolster their egos and self-esteem, narcissistic individuals are capable of inflating reports of their performance when there are positive social status implications. In this context, profit maximization via earnings management creates an image of financial performance that feeds narcissistic individuals' need for admiration and praise and their sense of importance. In the same conception as Hobson and Resuteck (2008), Olsen et al. (2013) highlight the positive correlation between narcissism and the unethical behaviors of accounting report manipulation, especially due to the fact that performance goals based on accounting numbers help to define CEO bonuses and compensation. Collins and Schmidt (1993) and Blickle, Schlegel, Fassbender, and Klein (2006) showed that so-called white collar crimes are more often committed by managers with a dark personality. Strong narcissistic traits are more evident in executives who have committed white collar crimes (Blickle et al., 2006).

Buchholz, Lopatta, and Maas (2014) showed that highly narcissistic CEOs are associated with earnings management, whose forms are configured as passports to bad managerial behavior. Frino et al. (2015) confirm that the most narcissistic CEOs are more likely to be involved in manipulating results, with the aim of presenting better performance, thus indicating a higher probability of false financial reports.

Olsen and Stekelberg (2016) found narcissistic CEO involvement in corporate tax evasion. As narcissists feel 
they are above the law and are aggressive in pursuing what they believe belongs to them, they are motivated to pursue rewards or desirable results. Ham et al. (2017) investigated the effect of narcissism in chief financial officers (CFOs) over the results of financial reports. These authors showed that CFOs with larger signatures present more sings of incorrect declarations and more evidence of earnings management.

When analyzing narcissism in unethical decision making, Amernic and Craig (2010) argued that since company directors can define and influence opportunistic conducts, especially using the results of financial accounting, these conducts become a personal test of success or failure. In this conception, Olsen et al. (2013) argue that the higher a company's earnings, the more the compliments and praise needed to bolster the inflated sense of ego presented by those individuals with a tendency for narcissistic behaviors.

When investigating narcissism in CEOs and the occurrence of frauds, Rijsenbilt and Commandeur (2013) found a positive and statistically significant relationship between these variables. Highly narcissistic CEOs can achieve greatness for their companies; however, if there is no control, this can result in unethical behavior and damage company interests. Johnson et al. (2013) showed that the narcissistic behavior of managers and willingness to commit fraud are significant and positively related to assessed risks of fraud.

\subsubsection{Psychopathy.}

When analyzing the behavior of successful corporate psychopaths, Gudmundsson and Southey (2012) identified attributes such as high levels of assertiveness and low affability traits, such as simplicity, altruism, complacency, and modesty. These professionals seek excitement in their activities, which is positively reflected in their high competence in organizations, order, effort, and selfdiscipline.

On the other hand, when they hold senior executive positions, corporate psychopaths look for gaps in the law to avoid or reduce taxes. Whenever possible, they manipulate share prices for their own benefit, without any concern for investors, pension funds, and employees. Corporate psychopaths involve corporations in illegal accounting practices, independent of the implications that can arise in the long term. Without the inhibiting effect of their conscience, corporate psychopaths are capable of lying, persuading, and manipulating in order to achieve their objectives: power, wealth, and status. They can be responsible for a considerable amount of bad organizational behavior, including accounting fraud, stock manipulation, unemployment, and environmental damage resulting from a lack of social responsibility (Boddy, 2006).

Psychopaths are capable of falsifying financial results in order to obtain a promotion (McCormick \& Burch, 2005), bonus, and other benefits, and even committing absolute fraud (Clarke, 2005) against the company that employs them. Individuals with a high level of psychopathy get involved in bad financial behavior, even in the presence of clear and probable punishment, especially due to the egotistical nature of such individuals and their need for reputation and image in the financial world. Those rich in psychopathy have displayed more persistence when playing, leading to greater financial losses for the next participant, without being concerned about the probable punishment (Jones, 2014).

\subsubsection{Machiavellianism.}

By concentrating studies on Machiavellian traits, Jones and Paulhus (2011) revealed strategy, tactics, and a rational decision-making style, by considering all the costs and benefits for resolving problems. In contrast, Machiavellian people are manipulative and strategic, with a pragmatic ethical sense and propensity for using tactics with a view to achieving their objectives, in order to obtain personal gains (Jones \& Paulhus, 2009).

When analyzing the relationship between Machiavellianism and unethical behavior, Murphy (2012) investigated rationalization as being one of the three characteristics that compose the fraud triangle and proved that this relationship presupposes the existence of false declarations in financial reports. Along these lines, Byington and Johnson (2011) showed the tendency for Machiavellian individuals to manipulate budgetary items.

The relationship between the Machiavellian traits and the decision to manage earnings was found by Shafer and Wang (2011). Within this same context, Vladu (2013) showed that a Machiavellian predisposition performs a central role in the decision to manage financial results, since individuals with a high score on the Machiavellian scale have less rigid views about the ethics of these practices in the short term, considering this type of management to be ethically acceptable.

Thus, based on the conceptual aspects and on the results of the studies presented, we elaborated the following research hypotheses:

- H1: There is a positive relationship between the moderate traits of the Dark Triad and a lower tendency to maximize personal and corporate gains by manipulating results. 
- H1a: There is a positive relationship between the moderate traits of Machiavellianism and a lower tendency to maximize personal and corporate gains by manipulating results.

- H1b: There is a positive relationship between the moderate traits of narcissism and a lower tendency to maximize personal and corporate gains by manipulating results.

- H1c: There is a positive relationship between the moderate traits of psychopathy and a lower tendency to maximize personal and corporate gains by manipulating results.

- H2: The interactions between the traits that compose the Dark Triad promote the tendency to maximize personal and corporate gains by manipulating results.
It is hoped that the differences between the levels and intensities of the traits (weak, moderate, and strong) are revealed. The weak trait is not highlighted in the literature, given that it is present in the population in general and does not generate consequences. The strong trait is emphasized in the literature and the results are unanimous: it reveals an insensitive, manipulative, and dishonest character. As for the moderate trait, which is barely explored in the literature, this can reveal a middle ground between the previous results and enable the confirmation of positive attitudes, as affirmed by Spain, Harms, and LeBreton (2014). The combined effect of $\mathrm{H} 2$ will enable it to be verified that those characteristics that are common among the 3 traits lead to more accentuated negative attitudes that are not extreme but are opportunistic.

\section{METHODOLOGY}

\subsection{Methodological Approach, Strategy, and Research Variables}

This investigation adopts the theoretical-empirical methodological approach. A survey was used as data collection strategy, involving a self-reporting questionnaire sent by email, given the difficulty involved in personally applying it to managers.

The Dark Triad was chosen as the independent variable as it is able to explain and predict the dependent variable - profit maximization. The research design was configured as shown in Figure 2, presenting the conceptual and operational variables, in accordance with the model from Libby, Bloomfield, and Nelson (2002).

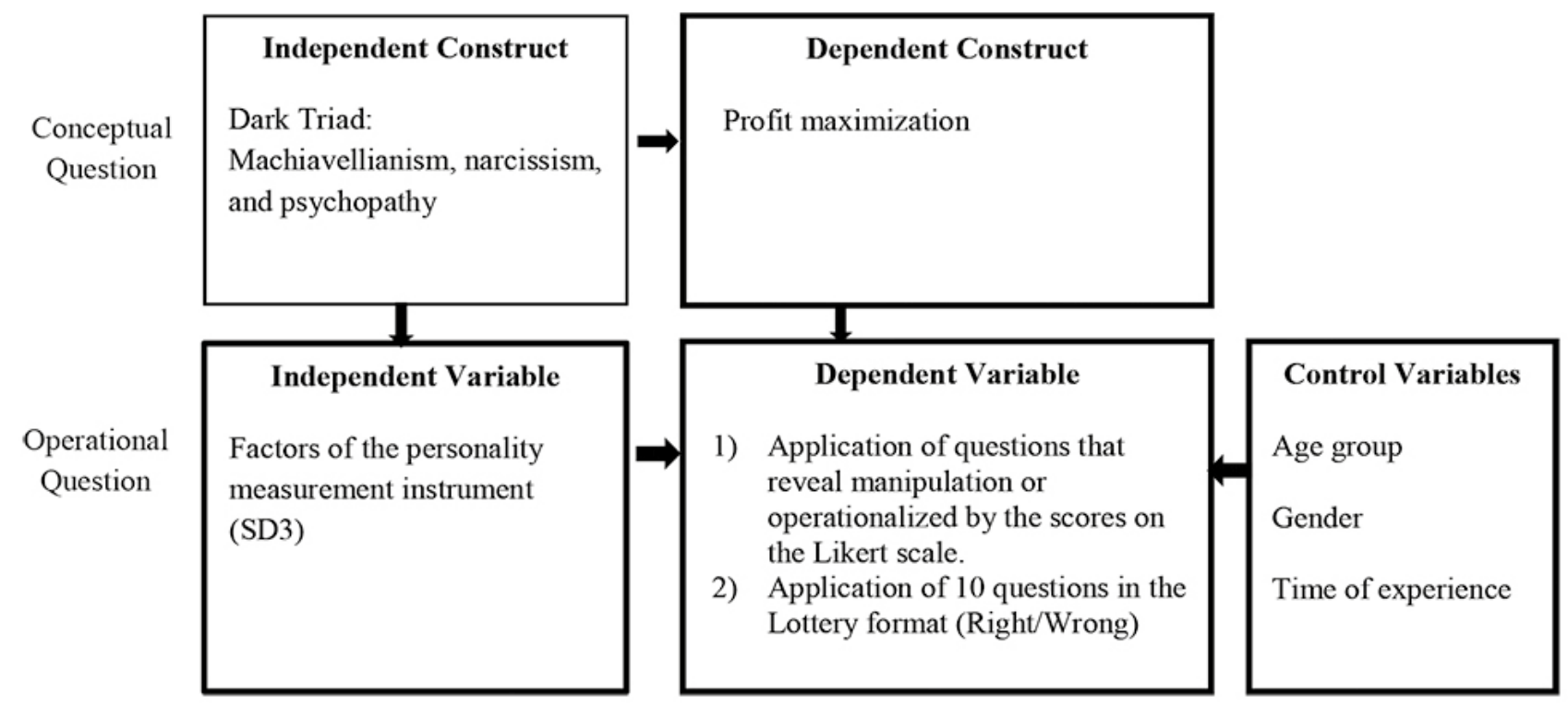

Figure 2 Conceptual and operational variables of the study.

Source: Elaborated by the authors. 
The age, gender, and time of experience variables were considered to be potential influencers of managers' choices since they are personal characteristics, which is a conception that is supported by Upper Echelons Theory.

\subsection{Procedures and Operationalization of the Data Collection Tool}

\subsection{1 "Short Dark Triad".}

The "Short Dark Triad" (SD3), proposed by Jones and Paulhus (2014) was used, with 9 brief assertions for each personality trait, using the Likert scale (1 to 5 points). In accordance with the research tool, the answers to the assertions (N2, N6, N8, P2, and P7) were reverted: answer 1 to 5 ; answer 2 to 4 ; and answer 3 remained the same with no reversion.

In order to establish the levels of the traits, the following criterion was adopted: first the mean for each individual and group (quantitative variable) was measured, and then terciles were used to divide the group into three bands: weak traits, moderate traits, and strong traits (qualitative variable). A means calculation was used as this is the current practice in studies in the area of psychology (Campbell et al., 2004; Jones \& Paulhus, 2014; Paulhus $\&$ Williams, 2002) and in the accounting area (Johnson et al., 2013; Majors, 2015; Murphy, 2012).

\subsubsection{Business simulation.}

Ten questions were elaborated involving a business simulation (BS) based on profit maximizing actions, focusing on 7 assertions in the Likert format ( 1 to 5 points), for possible financial maneuvers of an accounting nature, discussed by Schilit and Perler (2010). The other three assertions were included to divert the focus from the theme investigated. The contextualization of the BS suggests that managers' decisions will impact their performance, the possibility of losing their position, and dismissal of employees who work in the team. The assertions are:

I convene the team to present the results and ask for an effort to achieve the goal in the remaining two days.

I verify with the sales sector the possibility of bringing forward the recording of sales that will be realized in the following month.

I verify whether the current maintenance expenses can be postponed.

I invite colleagues to dinner to reduce day-to-day tensions. I verify whether it is possible to assign miscellaneous expenses to Permanent Assets.

I verify whether the financial charges from the current month can be posted in future periods.

I observe the possibility of postponing probable losses indicated by the legal sector related to employment proceedings that should be recorded in the current month.

I do not communicate that the stock stored at a particular location is lost due to some technical problem.

I do not inform accounting and maintain an important balance to be received from a bankrupt client in Assets.

I relax, aware that I did everything possible to achieve the results.

In order to operationalize the answers derived from the BS method, the mean (quantitative variable) was taken and then the group was divided by the median, that is, into two bands - manipulation/non-manipulation (qualitative variable).

\subsubsection{Lottery.}

The lottery $(\mathrm{L})$ method was developed to complement that of the BS and constituted with the aim of detecting personal profit maximizing behavior, for joint analysis, using 10 questions of a managerial and financial nature, in the "lottery" format (right/wrong), with the aim of making the respondents answer the questions and participate in a draw for two minitablets, as shown in Table 1.

Table 1

Lottery

\begin{tabular}{|c|c|c|}
\hline Assertions & Right & Wrong \\
\hline \multicolumn{3}{|l|}{$\begin{array}{l}1 \text {-The components of the financial environment are managers responsible for the investment and financing decisions, } \\
\text { investors, and financial markets. }\end{array}$} \\
\hline \multicolumn{3}{|l|}{$\begin{array}{l}2 \text {-If the managers make unsuitable decisions, inconsistent with maximizing share values, the investors will buy more } \\
\text { shares, exerting downward pressure on the price. }\end{array}$} \\
\hline \multicolumn{3}{|l|}{3 -The Ebitda is an accounting indicator that measures the ability to generate gross operating cash flow. } \\
\hline \multicolumn{3}{|l|}{$\begin{array}{l}4 \text {-The main aim of cash flow management is to increase the amount of cash kept at the minimum limit needed for the } \\
\text { business to operate. }\end{array}$} \\
\hline \multicolumn{3}{|l|}{$\begin{array}{l}5 \text {-Discounted cash flows are future cash flows expressed at present value, in which the rate of return on the investment } \\
\text { is related with the cost of capital employed. }\end{array}$} \\
\hline \multicolumn{3}{|l|}{$6-$ In all situations, the equilibrium point is the desirable target price for a company. } \\
\hline \multicolumn{3}{|l|}{7 -The master budget is a comprehensive operational plan, composed of various joint department and activity budgets. } \\
\hline \multicolumn{3}{|l|}{8 -Maximizing the internal rate of return on an investment implies maximizing the company's absolute profit. } \\
\hline 9 -The sales price of a product or service must be at least equal to the variable cost of producing or selling it. & & \\
\hline 10 - Aligning production with supply is a critical decision in the corporate environment. & & \\
\hline
\end{tabular}

Source: Elaborated by the authors. 
When each respondent concluded the answers to the $\mathrm{L}$ method questions, or when the time limit for answering the questions had expired, he/she was asked to save the answers and verify the right ones. At this point, one of the following situations could occur:

a. Congratulations! You got all the questions right. You could be one of the winners! (In this situation, there was no way to detect unethical behavior). Click SAVE and FINISH.

b. Unfortunately, you did not get all the questions right. But you can participate in the draw if your number of right answers is equal to that of the other participants. For this, click SAVE and FINISH.

When the respondent clicked SAVE, the following error message illustrated in Figure 3 appeared.

Fatal error: Allowed memory size of 12582912 bytes exhausted (tried to allocate 23456789 bytes) in save_questionare.php

It was not possible to save your answers. To finish the questionnaire, state whether you got all the questions right:

YES, I got all the questions right

NO, I got some questions wrong

Figure 3 Bluff

Source: Elaborated by the authors.

The error message was inserted on purpose as a "bluff", with the aim of observing the respondent's tendency, when faced with two alternatives (yes/no), to decide to manipulate the results, given that the individual had already been informed about his/her result/performance. If the participants clicked "I got all the questions right", even knowing that they had not, they manipulated their decision and revealed opportunistic behavior.

So that the respondents would not suspect the main aim of the study, nor consult the internet to answer the questions, the following measures were adopted: (a) only 4 minutes were made available to save the answers (a chronometer was included on the screen); (b) the questions were elaborated in such a way that it was not possible to quickly verify the answers on the internet or using other sources; (c) the questions were shown one by one; (d) a device was included to prevent the questions being copied; and (e) an automatic blocking function was included in the questionnaire after it was answered in full.

To justify the time limitation for the answers, the wording of the L method communicated that the intention of the study was to detect the manager's ability to make quick decisions, with the aim of maximizing company profits. However, this strategy was adopted with the previously reported objectives and to verify whether, under pressure, especially in the context of a business simulation, the individuals had a tendency to maximize their gains (performance) by manipulating the results. At the same time, the prize was used as an incentive and strategy for detecting the intention of the individuals when encouraged to behave opportunistically.

For the parametrization of the binary-nature (yes/no) variables, "yes" was categorized for manipulation and "no" for non-manipulation (qualitative variable). With the aim of verifying the tendency to manipulate in an integrated way, a binary variable called joint manipulation (JM) was categorized, based on the following procedure: if the individual manipulated via 1 or via the 2 methods at the same time, he/she had a tendency to manipulate results. This criterion was also adopted via the presence of a correlation $(r=0.282, p<0.001)$ between the BS method and the $\mathrm{L}$ method. The operationalization of the variable was also binary (yes/no) and "yes" was categorized for manipulation and "no" for non-manipulation (qualitative variable).

\subsection{Statistical Approach}

The following statistical techniques were applied: descriptive, correlation, one-way ANOVA hypothesis 
tests, Mann-Whitney test, and logistic regression, these last ones being to validate hypotheses $\mathrm{H} 1$ and $\mathrm{H} 2$. The correlation technique enabled the association to be verified between the personality traits, as well as the relationship between the personality trait and profit maximization variables. The logistic regression was applied due to the binary nature of the dependent variables resulting from the $\mathrm{L}$ and JM methods. This technique enabled the effects of each of the variables inserted into the model to be verified, along with the probability of occurrence of a particular event and the individual contribution of each of the predictors.

\section{RESULTS ANALYSIS}

\subsection{Applying the Study}

\subsubsection{Participants.}

The study was carried out on 263 managers with the following demographic profile: gender (63.1\% male), age group (10.3\% between 18 and 25; 54\% between 26 and $35 ; 22.1 \%$ between 36 and 45 ; and $13.7 \%$ over 45 ). Their experience in management was quite stratified, with higher incidences for 10 months (20\%), 24 months (41\%), 36 months (19\%), and 72 and 120 months (14\%).

\subsubsection{Results and discussions.}

Machiavellianism presented the highest mean (2.9155) of the 3 traits. Regarding the frequency of the traits by level, revealed based on the tercile, Machiavellianism and psychopathy presented the highest proportions (38\% and $41.1 \%$ in the low ranges, respectively) and narcissism presented the highest proportion in the moderate ranges (43\%). Division by level of intensity of the traits into low and high has been used in studies such as those from Johnson et al. (2013), Majors (2015), and Murphy (2012). This procedure enables a perception of the strength of the traits to differentiate a higher and lower tendency in an individual to display opportunistic conducts in the corporate environment. As psychopathy presented the lowest mean in relation to the other 2 traits, the tercile also reflects the lowest value among the high, moderate, and low ranges.

Moreover, finding the moderate level represents an additional contribution to the research that has studied this topic, with the expectation that this level can present attitudes that reveal the desirable and positive characteristics of each personality trait, in the corporate environment, instead of the negative and opportunistic side of the triad. As Chatterjee and Hambrick (2007) state, moderate narcissism is essential to human beings.

With regards to the frequency of profit maximization via manipulation of results, the results indicated a higher incidence of non-opportunistic conducts, both for the
BS method (53.2\%) and for the L method (83.3\%). However, analyzing the 2 methods together, $51.3 \%$ of the respondents presented the behavior. On this point, it is worth explaining that 30 respondents showed a tendency for manipulation via the 2 methods at the same time.

As it is measured by the Likert scale, the BS method reflects the respondent's agreement and disagreement with regards to manipulating results and enables an attitudinal analysis, without necessarily confirming the action of manipulation, but merely some predisposition. As for the L method, the respondents present opportunistic behavior when they indicate having got all the questions right, even after being informed that they did not. The 2 methods together reflect both attitude and opportunistic behavior. As was already mentioned previously, this combination of the 2 methods was also enabled by the statistical correlation revealed.

These results are consistent with Giammarco, Atkinson, Baughman, Veselk, and Vernon (2013), whose evidence indicates that by lying individuals with a Machiavellian, psychopathic, or narcissistic tendency believe that they are better than the average person, in a wide range of situations. Machiavellians are people who show the greatest capacity for cheating, followed by psychopaths, with narcissists coming in third position. According to Austin, Farrelly, Black, and Moore (2007), Machiavellians have a large capacity for emotional manipulation.

When the Pearson correlation between the variables was analyzed, a positive and significant relationship was observed between Machiavellianism and narcissism ( $\mathrm{r}=$ $0.209, p<0.05)$, Machiavellianism and psychopathy ( $\mathrm{r}$ $=0.349, p<0.05)$, and narcissism and psychopathy $(\mathrm{r}=$ $0.251, p<0.05)$. The BS method was revealed to be positive and significant with the 3 personality types, showing more intensity with psychopathy $(\mathrm{r}=0.232, p<0.05)$.

By analyzing the correlation between Machiavellianism and psychopathy, it can be inferred that there is a greater propensity for psychopaths to get involved in misleading 
management tactics in order to obtain their own gains, without feeling guilty about the harm caused to others. If they need to persuade and convince others in relation to adopting a misleading management tactic, they tend to lie without feeling remorse.

Regarding the correlation between Machiavellianism and narcissism, the results suggest that narcissists have a greater tendency to use manipulative strategies than Machiavellians in order to feed their sense of greatness and exhibitionism, in the search for praise and status. Despite being the lowest of the 3 , the correlation between narcissism and psychopathy suggests, among other behaviors, a search for self-esteem and self-promotion in the corporate environment.

The Spearman correlation, used due to the qualitative nature of the variables categorized in the L and JM method, confirms the association between the traits and the JM (Machiavellianism: $\mathrm{r}=0.230, p<0.05$; narcissism: $\mathrm{r}=$ $0.108, p<0.10$; psychopathy: $\mathrm{r}=0.165, p<0.05)$ and the correlation between the L and JM methods $(r=0.436$, $p<0.05$ ).

The results enable the inference that there is a significant relationship between the Dark Triad traits and profit maximization, thus corroborating with the previous studies that related traits of Machiavellianism (Austin et al., 2007; Hartman \& Mass, 2010; Murphy, 2012; Shafer \& Wang, 2011), narcissism (Frino et al., 2015; Ham et al., 2017; Johnson et al., 2013; Rijsenbilt \& Commandeur, 2013), and psychopathy (Boddy, 2006; Clarke, 2005; Jones, 2014) with earnings management and corporate fraud.

In addition, the findings confirm the base theory of this investigation, which is that personality influences individuals' interpretations and consequently affects their choices (Hambrick \& Mason, 1984; Hambrick, 2007). After confirming the homogeneity of the variances using the Levene test - Machiavellianism ( $p=0.557)$, narcissism ( $p=0.795)$, and psychopathy ( $p=0.715)$ - the one-way ANOVA statistical method was applied, using the BS method, as shown in Table 2 . The $\mathrm{F}$ test revealed the values $\mathrm{F}(2.260)=7.006, p=0.001$ for Machiavellianism; $\mathrm{F}(2.260)=1.717, p=0.182$ for narcissism; and $\mathrm{F}(2.260)$ $=8.071, p<0.001$ for psychopathy. These results suggest that there is a difference in profit maximizing attitudes between the individuals, in accordance with the low, moderate, and high levels for the managers who display traits of Machiavellianism and psychopathy.

\section{Table 2}

ANOVA: business simulation

\begin{tabular}{cccccccccccccccc}
\hline & \multicolumn{1}{c}{ Machiavellianism } & \multicolumn{1}{c}{ Narcissism } & \multicolumn{4}{c}{ Psychopathy } \\
\hline & SS & DF & MS & F & Sig. & SS & DF & MS & F & Sig. & SS & DF & MS & F & Sig. \\
\hline Between groups & 9.67 & 2 & 4.836 & 7.006 & 0.001 & 2.464 & 2 & 1.232 & 1.717 & 0.182 & 11.054 & 2 & 5.52 & 8.071 & 0,000 \\
\hline In groups & 179.43 & 260 & 0.690 & & & 186.646 & 260 & 0.718 & & & 178.056 & 260 & 0.685 \\
\hline Total & $\mathbf{1 8 9 , 1 1}$ & $\mathbf{2 6 2}$ & & & & $\mathbf{1 8 9 , 1 1}$ & $\mathbf{2 6 2}$ & & & & $\mathbf{1 8 9 , 1 1 0}$ & $\mathbf{2 6 2}$ & \\
\hline
\end{tabular}

$S S=$ sum of the squares; $M S=$ mean square.

Source: Elaborated by the authors.

When analyzing the difference between the means for the traits, using the L and JM methods, it was observed, via the Mann-Whitney test, that there is a difference in the manipulation of results for the Machiavellian and psychopathic traits (Table 3).

As for narcissism, this did not present any difference in mean in any of the methods adopted here for detecting results manipulation. It is inferred that this finding could be related with the secretive nature of the data collection for this study, which did not motivate the difference of intensity of the trait, given the need of narcissists to be glorified and applauded for their conquests, especially when they stand out from the rest. As failure and criticism scare narcissists, they restrain themselves to hide and protect their greatness and their sense of superiority and can show a lack of willingness to take risks in competitive situations (Mecler (2015). Another point to be verified in previous studies is the prize offered, which may not have been enough to motivate manipulation to maximize gains. This finding refutes the assumption that narcissists exhibit a moderate and positive tendency. 
Table 3

Mann-Whitney test: lottery and joint manipulation

\begin{tabular}{cccccccc}
\hline $\begin{array}{c}\text { Dependent } \\
\text { variable }\end{array}$ & Test & \multicolumn{2}{c}{ Machiavellianism } & \multicolumn{2}{c}{ Narcissism } & \multicolumn{2}{c}{ Psychopthy } \\
Lottery & Mann-Whitney & 0.453 & Does not reject H0 & 0.373 & Does not reject H0 & 0.206 & Does not reject H0 \\
\hline $\begin{array}{c}\text { Joint } \\
\text { manipulation }\end{array}$ & Mann-Whitney & $\mathbf{0 . 0 0 0}$ & Rejects Ho & 0.82 & Does not reject H0 & \multirow{0}{*}{$\mathbf{0 . 0 0 7}$} & Rejects Ho \\
\hline$P$
\end{tabular}

$P<0.05$ is in bold.

Source: Elaborated by the authors.

With the aim of simultaneously comparing each level of the traits that compose the Dark Triad, it was observed using the Bonferroni test (post hoc ANOVA test) that the individuals with moderate and strong Machiavellian traits exhibit a significant difference ( $p=0.006$ and $p=0.004$ ) in relation to the BS in comparison with the individuals that show weak traits. Via the JM method, Machiavellianism also differs for the moderate $(p=0.055)$ and strong $(p$ $<0.001)$ traits. As for the L method, this did not show any differences.

From the Tukey test it is observed that the moderate level of Machiavellianism is closer to the high level, with means of 0.5432 and 0.6585 , respectively, which denotes a greater tendency among these managers to intentionally manipulate results, based on strategies that enable personal goals and objectives to be achieved. It is also inferred that managers with moderate Machiavellianism tend to adopt managerial manipulation tactics based on calculations lacking moral and ethical standards that are geared towards long-term future gains, in a similar behavior to managers who exhibited strong traits. Hartog and Belschak (2012) highlight that when leaders are highly Machiavellian, the positive effects of the leader's behavior can end up being suppressed.

From the Bonferroni and Tukey tests, narcissism did not reveal any differences of means between the weak traits and the moderate traits and the strong traits via the 3 methods (BS, L, and JM). The Tukey test presents the formation of a single subgroup, confirming the previous results.

When psychopathy is analyzed, it is possible to note from the Bonferroni test that those individuals with weak and moderate psychopathic traits exhibit significant differences $(p<0.001$ and $p=0.008)$ via the BS method in relation to individuals that show strong traits. The Tukey test corroborates the results found previously by demonstrating that subgroup 1, composed of the decision of individuals with weak traits and moderate traits (means of 2.2169 and 2.2780, respectively), presents more significantly similar and closer statistical means, differing from subgroup 2, composed of the strong traits.

The results also suggest that the strong traits differ from the moderate traits $(p=0.017)$ and the weak traits $(p=0.027)$ when analyzing the JM method. The Tukey test confirms the formation of subgroup 1, composed of the weak traits and the moderate traits (means of 0.4324 and 0.4630 , respectively, significant and more similar) and of subgroup 2 (mean of 0.6543 ), composed of the strong traits. The L method did not show any differences.

With this result, it is inferred that the moderate traits reveal a greater tendency for managers to maximize their gains by manipulating results. The greater approximation between the weak traits and moderate traits confirms the assumption that psychopathy exhibits a moderate and positive tendency in the sample studied. This finding suggests that managers with moderate traits use intelligence and moderate impulsivity to leverage and do good deals, as well as using charm, communication skills, creativity, vision, courage, and the ability to make difficult decisions in a positive way within the corporate environment.

Applying the logistic regression to test $\mathrm{H} 2$, the Dark Triad traits were grouped interactively as $\mathrm{Mach}^{\star} \mathrm{Narc}^{\star} \mathrm{Psyc}$ to observe the combined effect using the evidence of a positive and significant correlation between the 3 traits and the evidence that manipulation is a characteristic that is common to the triad. The same procedure was adopted for the variables Experience ${ }^{\star}$ Age group, using the evidence of the correlation between them $(r=0.683$, $p<0.001$ ).

The Chi-squared test showed that the combined coefficients are statistically significant for the model being studied, in light of the BS (sig. 0.000) and JM (sig. 0.000) methods. This result enables it to be interpreted that the model is able to accurately predict the investigation.

The $\mathrm{Mach}^{\star} \mathrm{Narc}^{\star}$ Psyc interaction is significant and presents a positive sign, showing that the positive variation of this variable leads to an increase in the probability of managers deciding to manipulate results, measured by the $\mathrm{BS}, \mathrm{L}$, and JM methods, when the other variables remained 
constant. This denotes that if the interactive variable Mach ${ }^{\star}$ Narc $^{\star}$ Psyc increased by one unit, the estimated logit increases by an average of $1.069,1.025$, and 1.063, suggesting a positive relationship between the decision to manipulate results and the personality traits, measured by the BS, L, and JM methods. The gender variable was also shown to be positive via the $\mathrm{L}$ method and suggests a positive relationship with the logit.

Regarding the significance of the variables individually, the Wald test shows the significance of the interactive variable $\mathrm{Mach}^{\star} \mathrm{Narc}^{\star} \mathrm{Psyc}$, indicating that it is statistically significant as a predictive factor for the decision to manipulate results. The Experience ${ }^{\star}$ Age group interactive variable was also shown to be significant and a predictive factor when analyzing the BS method. According to Bommer, Gratto, Gravander, and Tuttle (1987), in situations in which there are ethical dilemmas, individual attributes (personality, demographic profile, personal objectives, position/status, and experiences) are necessary conditions for the perception and selection of alternatives that reflect ethical or unethical decision-making behavior. They also emphasize that when there are situations of conflict between the personal values of the manager and the objectives of the organization, the former chooses the path that serves his/her own interests, especially when his/her career progress is in play.

In relation to the other variables included in the model, although they have not been shown to be significant, the Chi-squared test showed the significance of the model studied, when analyzing the variables together (Table 4).

\section{Table 4}

Coefficients, signs and Wald test

\begin{tabular}{|c|c|c|c|c|c|c|}
\hline & \multirow{2}{*}{ Variables } & \multirow{2}{*}{ Expected sign } & \multirow{2}{*}{ Sign found } & \multirow{2}{*}{ B Coefficient } & \multirow{2}{*}{$\operatorname{Exp}(\beta)$ Coefficients } & \multirow{2}{*}{$\begin{array}{c}\text { Wald Test } \\
\text { p-value }\end{array}$} \\
\hline & & & & & & \\
\hline \multirow{4}{*}{ BS } & Mach.*Narc.*Psyc. & + & + & 0.067 & 1.069 & 0.000 \\
\hline & Experience*Age Group & $+/-$ & - & 0.001 & 0.999 & 0.086 \\
\hline & Gender & $+/-$ & - & 0.202 & 0.817 & 0.338 \\
\hline & Constant & $+/-$ & - & 1.015 & 0.362 & 0.016 \\
\hline \multirow{4}{*}{ L } & Mach.*Narc. ${ }^{*}$ Psyc. & + & + & 0.025 & 1.025 & 0.235 \\
\hline & Experience*Age Group & $+/-$ & - & 0.061 & 0.941 & 0.823 \\
\hline & Gender & $+/-$ & + & 0.000 & 1.000 & 0.370 \\
\hline & Constant & $+/-$ & - & 1.909 & 0.148 & 0.000 \\
\hline \multirow{4}{*}{$J M$} & Mach.*Narc.*Psyc. & + & + & 0.061 & 1.063 & 0.001 \\
\hline & Experience*Age Group & $+/-$ & - & 0.069 & 0.934 & 0.743 \\
\hline & Gender & $+/-$ & - & 0.001 & 0.999 & 0.028 \\
\hline & Constant & $+/-$ & - & 0.801 & 0.449 & 0.056 \\
\hline
\end{tabular}

$P<0.10$ is in bold. Variables that entered into Step 1: Mach*Narc*Psyc, Gender, Experience*Age Group. BS = business simulation; $L=$ lottery; $M=$ joint manipulation.

Source: Elaborated by the authors.

The finding is consistent with the results of Lee and Ashton (2005), which indicated that all the Dark Triad traits are strongly and negatively correlated with the Honesty-Humility dimension of the Hexaco model, clearly indicating that this triad has common characteristics that presuppose a strong tendency for dishonesty and opportunism.

In this context, it is inferred that dark personalities leave individuals vulnerable to ethical lapses that can compromise a company in the short and/or long term. On this point, Ferrel and Gresham (1985) state that ethical or unethical decisions are influenced by individual factors (the individual's cognitive structure, knowledge, values, beliefs, attitudes, and intentions) and by the opportunity for action.

In summary, this study, supported by Upper Echelons Theory, revealed the moderate side of the personality traits and verified that for the Machiavellian and psychopathic traits the tendencies were presented as opposing. If on one hand moderate Machiavellianism displayed a greater similarity with individuals who are rich in Machiavellianism, moderate psychopathy displayed a greater approximation with weak psychopathy, which supports H1c. It was also shown that there is a positive relationship between the interaction of the traits that compose the Dark Triad and profit maximization, which supports $\mathrm{H} 2$. 
It is inferred that moderate Machiavellians are more likely to display opportunistic tendencies in the corporate environment, thus going against the expectation of positive behavior, while moderate psychopathy suggests positive and desirable behavior, which is consistent with the expectations of the researchers from this study, who believe that the Dark Triad personality traits can also reveal their positive side in the organizational environment.

The rejection of $\mathrm{Hla}$ and $\mathrm{H} 1 \mathrm{~b}$ elicits a continuation of the studies on the topic, in particular due to the cultural differences, the setting in which the study is applied, and the subjects of the research.

\section{CONCLUSION}

The moderate traits of Machiavellianism were shown to be closer to the strong traits, which enables it be inferred that there is greater tendency among managers to display opportunistic attitudes, with the cynicism that characterizes them, using strategies that uphold their reputation and enable them to achieve personal goals and objectives. As for the moderate traits of psychopathy, these exhibited a greater approximation and similarity to the weak traits and the moderate traits, enabling it to be inferred that there is a lower tendency for managers to maximize profit by manipulating results. This finding confirms the assumption that psychopathy exhibits a moderate and positive tendency in the sample studied. In this context, managers with moderate traits use intelligence and moderate impulsivity to leverage and make good deals, as well as charm, communication skills, creativity, vision, courage, and the ability to make difficult decisions in a positive way in the corporate environment.

The combined effect of the Dark Triad traits was shown to be significant and positive, showing that their positive variation leads to an increase in the probability of managers maximizing their gains by manipulating results. The interaction between experience and age group was also shown to be significant and a predictive factor, when the BS method was analyzed. Thus, in a similar way for the three traits, the chance of occurrence of profit maximization associated with manager opportunism and dishonesty in the corporate environment is estimated.

In this context, the aim of this study was achieved and the research problem was addressed. Although a difference of levels for narcissism was not revealed, which is a finding that may show bias or error in the application of this study, or as Furtner, Rauthmann, and Sachse (2011) state, the results of the investigations that discuss narcissism can differ and become desirable or undesirable, depending on the culture of the geographical setting that is the object of analysis. However, this finding may be a reflection of the conception of Giammarco et al. (2013) that, of the 3 traits, narcissism is the one that involves the lowest tendency to cheat.

The evidence found strengthens investigations in the accounting area, especially concerning the behavioral approach, by promoting its interface with psychology for an understanding of how personality, values, and experience influence managers' choices when conducting business and how employees and companies are impacted by these decisions. It also enables future research to systematically analyze the moderate intensity of the triad, as well as corroborating with the finding that revealed the common characteristics of manipulation, insensitivity, and dishonesty - when the interactive effect between the traits was analyzed.

It is also worth noting some limitations of the study. Applying a self-reporting type personality questionnaire may lead to tendenciosity in the self-descriptions of the characteristics and the behavior of the respondents, which may show some bias, especially if they find it difficult to answer questions about themselves objectively. In addition, the method for capturing profit maximization via results manipulation involves a delicate, complex path that is difficult to measure, given the sensitivity of the topic.

\section{REFERENCES}

Abatecola, G., Mandarelli, G., \& Poggesi, S. (2013). The personality factor: how top management teams make decisions. A literature review. Journal of Management \& Governance, 17(4), 1073-1100. Retrieved from https://doi. org/10.1007/s10997-011-9189-y

Almeida, O. P., Laranjeira, R., \& Dratcu, L. (1996). Manual de psiquiatria. Rio de Janeiro: Guanabara Koogan.
Amernic, J. H., \& Craig, R. J. (2010). Accounting as a facilitator of extreme narcissism. Journal of Business Ethics, 96(1), 79-93.

Austin, E., Farrelly, D., Black, C., \& Moore, H. (2007). Emotional intelligence, machiavellianism and emotional manipulation: does EI have a dark side? Personality and Individual Differences, 43, 179-189. 
Babiak, P., Neumann, C., \& Hare R. D. (2010). Corporate psychopathy: talking the walk. Behavioral Sciences and the Law, 28(2), 174-193.

Belschak, F. D., Hartog, D. N., \& Kalshoven, K. (2015). Leading Machiavellians: how to translate Machiavellians' selfishness into pro-organizational behavior. Journal of Management, 41(7), 1934-1956.

Blickle, G., Schlegel, A., Fassbender, P., \& Klein, U. (2006). Some personality correlates of business white-collar crime. Applied Psychology: An International Review, 55(2), 220-233.

Boddy, C. R. (2006). The dark side of management decisions: organizational psychopaths. Management Decision, 44(10), 1461-1475.

Bommer, M., Gratto, C., Gravander, J., \& Tuttle, M. (1987). A behavioral model of ethical and unethical decision making. Journal of Business Ethics, 6, 265-280.

Bowditch, J. L., \& Buono, A. F. (1992). Elementos de comportamento organizacional. São Paulo: Pioneira.

Brown, T. J. (2014). Advantageous comparison and rationalization of earnings management. Journal of Accounting Research, 52(4), 849-876.

Buchholz, F., Lopatta, K., \& Maas, K. (2014). The strategic engagement of narcissistic CEOs in earnings management (Working Paper). Retrieved from http://dx.doi.org/10.2139/ ssrn. 2520528

Byington, J. R., \& Johnson, G. H. (2011). Machiavellianism and accounting competence: effects on budgetary attitudes. Journal of Applied Business Research, 6(3), 98-104.

Campbell, W. K., Hoffman, B. J., Campbell, S. M., \& Marchisio, G. (2011). Narcissism in organizational contexts. Human Resource Management Review, 21(4), 268-284.

Chatterjee, A., \& Hambrick. D. C. (2007). It's all about me: narcissistic chief executive officers and their effects on company strategy and performance. Administrative Science Quarterly, 52(3), 351-386.

Clarke J. (2005). Working with monsters. How to identify and protect yourself from the workplace psychopath. Sidney: Random House.

Cohen, J., Ding, Y., Lesage, C., \& Stolowy, H. (2010). Corporate fraud and managers' behavior: evidence from the press. Journal of Business Ethics, 95, 271-315.

Collins, J. M., \& Schmidt, F. L. (1993). Personality, integrity, and white-collar crime: a construct validity study. Personnel Psychology, 46(2), 295-311.

Crocker, K. J., \& Slemrod, J. (2007).The economics of earnings manipulation and managerial compensation. The RAND Journal of Economics, 38(3), 698-713.

Cyert, R. M., \& March, J. G. (1963). A behavioral theory of the firm. Englewood Cliffs, NJ: Prentice-Hall.

Deutschman, A. (2005). Is your boss a psychopath? Fast Company, 96, 44 .

D'Souza, M. F. (2016). Manobras financeiras e o dark triad: o despertar do lado sombrio na gestão (Doctoral Dissertation). São Paulo: Universidade de São Paulo.

Dworkis, K. (2013). The interactive effects of incentive threshold and narcissism on managerial decision-making (Doctoral
Dissertation). Los Angeles, CA: University of Southern California.

Farwell, L., \& Wohlwend-Lloyd, R. (1998). Narcissistic processes: optimistic expectations, favorable self-evaluations, and self enhancing attributions. Journal of Personality, 66(1), 65-83.

Ferrell, O. C., \& Gresham, L. G. (1985). A framework contingency ethical decision understanding making in marketing. Journal of Marketing, 49(3), 87-96.

Fishbein, M., \& Ajzen, I. (1975). Belief, attitude, intention, and behavior: an introduction to theory and research. Reading, MA: Addison-Wesley.

Frino, A., Lim, M. Y., Mollica, V., \& Palumbo, R. (2015). CEO narcissism and earnings management (Working Paper). Retrieved from http://dx.doi.org/10.2139/ssrn.2539555

Furtner, M. R., Rauthmann, J. F., \& Sachse, P. (2011). The selfloving self-leader: an examination of the relationship between self-leadership and the dark triad. Social Behavior and Personality, 39(3), 369-380.

Giammarco, E.A., Atkinson, B., Baughman, H. M., Veselka, L., \& Vernon, P. A. (2013). The relation between antisocial personality and the perceived ability to deceive. Personality and Individual Differences, 54(2), 246-250.

Gudmundsson, A., \& Southey, G. (2012). Leadership and the rise of the corporate psychopath: what can business schools do about the 'snakes inside'? Social \& Behavioral Research in Business, 2(2), 18-27

Ham, C., Lang, M. H., Seybert, N., \& Wang, S. (2017). CFO narcissism and financial reporting quality. Journal of Accounting Research, 55, 1089-1135. doi:10.1111/1475679X.12176

Hambrick, D. C. (2007). Upper echelons theory: an update. Academy of Management Review, 32(2), 334-343.

Hambrick, D. C., \& Mason, P. A. (1984). Upper echelons: the organization as a reflection of its top managers. Academy of Management Review, 9(2), 193-206.

Hartmann, F. G. H., \& Maas, V. S. (2010, January). Why business unit controllers create budget slack: involvement in management, social pressure, and machiavellianism. Behavioral Research in Accounting, 22(2), 27-49.

Hartog, D. N. H., \& Belschak, F. D. (2012). Work engagement and Machiavellianism in the ethical leadership process. Journal Business Ethics, 107(1), 35-47.

Healy, P. M. (1985). The effect of bonus schemes on accounting decisions. Journal of Accounting and Economics, 7(1), 85-107.

Hobson, J. L., \& Resutek, R. J. (2008). More than money: the effects of social status and narcissism on manager reporting behavior (Working Paper). Retrieved from http://10.2139/ ssrn. 1270677

Holthausen, R. W., Larcker, D. F., \& Sloan, R. G. (1995). Annual bonus schemes and the manipulation of earnings. Journal of Accounting and Economics, 19(1), 29-74.

Jain, K., \& Bearden, J. N. (2011).Machiavellianism and overconfidence (Documento de Trabalho). Retrieved from http://papers.ssrn.com/sol3/papers.cfm?abstract_id=1774523

Johnson, E. N., Kuhn Jr., J. R., Apostolou, B., \& Hassell, J. M. (2013, February). Auditor perceptions of client narcissism as a fraud attitude risk factor. Auditing: A Journal of Theory \& Practice, 32(1), 203-219. 
Jones, D. N. (2014). Risk in the face of retribution: psychopathic individuals persist in financial misbehavior among the dark triad. Personality and Individual Differences, 67, 109-113.

Jones, D. N., \& Figueredo, A. J. (2013). The core of darkness: uncovering the heart of the dark triad. European Journal of Personality, 27(6), 521-531.

Jones, D. N. \& Paulhus, D. L. (2009). Machiavellianism. In M. R. Levy, \& R. H. Hoyle. (Ed.). Individual differences in social behavior (pp. 93-108). New York: Guilford.

Jones, D. N., \& Paulhus, D. L. (2011). Differentiating the dark triad within the interpersonal circumplex. In L. M. Horowitz, \& S. Strack. Handbook of interpersonal psychology (pp. 249269). New York: Wiley \& Sons.

Jones, D. N., \& Paulhus, D. L. (2014). Introducing the short dark triad (SD3): a brief measure of dark personality traits. Assessment, 21(1), 28-41.

Koch, C. (2010). An ethical justification of profit maximization. Society and Business Review, 5(3), 270-280.

Lee, K., \& Ashton, M. C. (2005). Psychopathy, machiavellianism, and narcissism in the five factor model and the Hexaco model of personality structure. Personality and Individual Differences, 38(7), 1.571-1.582.

Libby, R., Bloomfield, R., \& Nelson, M. W. (2002).Experimental research in financial accounting. Accounting, Organizations and Society, 27(8), 775-810.

March, J. G., \& Simon, H. A. (1958). Organizations. New York: Wiley \& Sons.

Maccoby, M. (2004, January). Narcissistic leaders: the incredible pros, the inevitable cons. The Harvard Business Review, 78(1), 68-78.

Majors, T. M. (2015).The interaction of communicating measurement uncertainty and the dark triad on managers' reporting decisions. The Accounting Review, 91(3), 973-992.

McCormick, I., \& Burch, G. (2005, November). Corporate behaviour; snakes in suits - fear and loathing in corporate clothing; they're glib, charming, deceitful and ruthless; they've been described as "snakes in suits" - and they're in an office near you. New Zealand Management, 52(10), 34.

Mecler, K. (2015). Psicopatas do cotidiano: como reconhecer, como conviver, como se proteger. Rio de Janeiro: Casa da Palavra.

Miller, N., \& Pazgal, A. (2002). Relative performance as a strategic commitment mechanism. Managerial and Decision Economics, 23(2), 51-68.

Murphy, P. R. (2012). Attitude, Machiavellianism and the rationalization of misreporting. Accounting, Organizations and Society, 37(4), 242-259.

Olsen, K. J., \& Stekelberg, J. M. (2016). CEO narcissism and corporate tax sheltering. The Journal of the American Taxation Association, 38(1), 1-22. Retrieved from https://doi. org/10.2308/atax-51251

Olsen, K. J., Young, S. M., \& Dworkis, K. (2013, in press). CEO narcissism and accounting: a picture of profits. Journal of Management Accounting Research. Retrieved from http://www2.aaahq.org/ata/meetings/2015/ CEONarcissismandCorporateTaxShelteringJATAConference.pdf

O'Reilly, C. A., Doerr, B., Caldwell, D. F., \& Chatman, J. A. (2013). Narcissistic CEOs and executive compensation (Working Paper). Retrieved from http://dx.doi.org/10.1016/j. leaqua.2013.08.002

Papadakis, V. M., \& Barwise, P. (2002, March). How much do CEOs and top managers matter in strategic decision-making? British Journal of Management, 13(1), 83-95.

Paulhus, D. L., \& Williams, K. (2002). The dark triad of personality: narcissism, Machiavellianism, and psychopathy. Journal of Research in Personality, 36(6), 556-563.

Peter, J., \& Olson, J. (2009). Comportamento do consumidor e estratégia de marketing ( $8^{\text {th }}$ ed.). São Paulo: McGraw-Hill.

Primeaux, P., \& Stieber, J. (1994). Profit maximization: the ethical mandate of business. Journal of Business Ethics, 13(4), 287294.

Quirin, M., Beckenkamp, E. M., \& Kuhl, E. J. (2008). Giving or taking: the role of dispositional power motivation and positive affect in profit maximization. Cognitive Studies in Economics and Social Sciences, 8(1), 109-126.

Rijsenbilt, A., \& Commandeur, H. (2013). Narcissus enters the courtroom: CEO narcissism and fraud. Journal of Business Ethics, 117, 413-429.

Rosenthal, S. A., \& Pittinsky, T. L. (2006). Narcissistic leadership. The Leadership Quarterly, 17, 617-633.

Schilit, H. M., \& Perler, J. (2010). Financial shenanigans. (3 ${ }^{\text {th }}$ ed.). New York: McGraw-Hill.

Shafer, W. E., \& Wang, Z. (2011). Effects of ethical context and Machiavellianism on attitudes toward earnings management in China. Managerial Auditing Journal, 26(5), 372-392.

Simon, H. A. (1970). Comportamento administrativo: estudo dos processos decisórios nas organizações administrativas (2a. ed.). Rio de Janeiro: Ed. FGV.

Smith, S. F., \&Lilienfeld, S. O. (2013). Psychopathy in the workplace: the knowns and unknowns. Aggression and Violent Behavior, 18, 204-218.

Spain, S. M., Harms, P., \& LeBreton, J. M. (2014). The dark side of personality at work. Journal of Organizational Behavior, 35, 41-60.

Troy, C., Smith, K. G., \& Domino, M. A. (2011). CEO demographics and accounting fraud: who is more likely to rationalize illegal acts? Strategic Organization, 9(4), 259-282.

Vaccari, L. C. (2014). O hiato entre atitude e comportamento ecologicamente conscientes: um estudo com consumidores de diferentes gerações (Doctoral Dissertation). Rio de Janeiro: Pontifícia Universidade Católica do Rio de Janeiro.

Vladu, A. B. (2013). Machiavellianism and short-term earnings management practices. Annales Universitatis: Apulensis Series Oeconomica, 15(2), 467-472.

Wexler, M. N. (2008). Conjectures on systemic psychopathy: reframing the contemporary corporation. Society and Business Review, 3(3), 224-238. 